\title{
PERHELATAN ATRAKSI BUDAYA BAKAR TONGKANG SEBAGAI SALAH SATU ATRAKSI BUDAYA DI RIAU
}

\section{The Bakar Tongkang Cultural Attraction As One Of The Riau Cultural Attraction}

\author{
Melisa $^{1)}$, Rianto $^{2)}$ \\ 1) Prodi Hospitality dan Pariwisata Universitas Bunda Mulia \\ 2) Prodi Pariwisata Sekolah Tinggi Pariwisata Trisakti
}

Diterima 2021 / Disetujui 2021

\begin{abstract}
Bakar Tongkang is one of the cultural attractions in Riau Province, namely Bagansiapiapi City. The Bakar Tongkang cultural attraction event is held annually for generations by the local community due to its unique culture and history.

This study was conducted to determine whether the Bakar Tongkang cultural attraction procession in Bagansiapiapi City, Riau Province can be an alternative cultural attraction in Riau Province which is made into a leading attraction. This study uses descriptive qualitative research involving informants representing the Tourism Office, accommodation industry players, transportation industry players, retail store industries, restaurant businesses, street vendors and tourists' views about this cultural attraction procession event as well as the community in Bagansiapiapi City and the organizing committee.

From the results of in-depth interviews and observations made by researchers based on in-depth questions, it was found that almost all informants who became sources of information stated that they strongly supported the existence of this cultural attraction event which was carried out regularly every year due to the positive impact of this cultural attraction procession event, namely the impact to the regional economy and Regional Original Income $(P A D)$ and become a leading attraction, in addition to the success of the procession of this cultural attraction, it also has the impact of traffic jams in the city of Bagansiapiapi during the process, rising prices for lodging, food and rickshaw prices as well as other negative impacts, namely waste.
\end{abstract}

Keywords : Cultural Attractions, Cultural Events, Barge Barge attraction procession

\begin{abstract}
ABSTRAK
Bakar Tongkang merupakan salah satu objek wisata budaya yang ada di Provinsi Riau yaitu Kota Bagansiapiapi. Ajang atraksi budaya Bakar Tongkang diadakan setiap tahun secara turun temurun oleh masyarakat setempat karena keunikan budaya dan sejarahnya.

Penelitian ini dilakukan untuk mengetahui apakah prosesi atraksi budaya Bakar Tongkang di Kota Bagansiapiapi Provinsi Riau dapat menjadi alternatif atraksi budaya di Provinsi Riau yang dijadikan sebagai atraksi unggulan. Penelitian ini menggunakan penelitian kualitatif deskriptif dengan melibatkan informan yang mewakili Dinas Pariwisata, pelaku industri akomodasi, pelaku industri transportasi, industri toko ritel, pelaku usaha restoran, pedagang kaki lima dan pandangan wisatawan tentang acara prosesi atraksi budaya ini serta masyarakat di Kota Bagansiapiapi dan sekitarnya. panitia penyelenggara.

Dari hasil wawancara mendalam dan observasi yang dilakukan peneliti berdasarkan pertanyaan mendalam, didapatkan bahwa hampir semua informan yang menjadi sumber informasi menyatakan sangat
\end{abstract}


mendukung adanya acara atraksi budaya ini yang dilaksanakan secara rutin setiap tahun karena dampak positif dari acara arak-arakan atraksi budaya ini yaitu berdampak pada perekonomian daerah dan Pendapatan Asli Daerah (PAD) dan menjadi daya tarik unggulan, selain keberhasilan prosesi atraksi budaya ini juga memiliki dampak kemacetan lalu lintas di kota Bagansiapiapi selama proses, kenaikan harga penginapan, harga makanan dan becak serta dampak negatif lainnya yaitu sampah.

Kata Kunci: Atraksi Budaya, Acara Budaya, Prosesi atraksi Tongkang

\section{PENDAHULUAN}

Kota Bagansiapiapi, atau dalam Bahasa Mandarin 峇眼亞比(Bāyănyàbǐ) merupakan sebuah kota kecil yang terletak ada di Provinsi Riau. Menurut cerita masyarakat yang sudah turun temurun, Kota kecil ini awalnya di temukan dan di kembangkan oleh orang tionghoa yang berasal dari songkhla di Thailand yang mereka sebenarnya adalah perantau Cina dari Tang Ua di Xiamen, wilayah provinsi Fujian,Tiongkok Selatan. Pada tahun 1820 silam dengan mengunakan tongkang dan dipimpin oleh Ang Mie Kui besama 17 orang lainnya dengan membawa serta patung dewa Tai Sun Ong Ya dan patung Kie Hu Ong ya. Menurut keyakinan mereka, para dewa akan memberikan keselamatan selama pelayaran. Petunjuk akhirnya diberikan oleh sang dewa, setelah melihat cahaya api yang berkelap kelip dan mereka mengikutinya sampai kedaratan yang sekarang dikenal dengan nama Bagansiapiapi. Berdasarkan versi perantau Cina yang biasa menyebut Bagansiapiapi dengan "Bagan api" berasal penemuan mereka melihat adanya api yang menyala dari kejauhan, "Bagan" berasal dari Sungai atau tempat sedangkan "api-api" berasal dari cahaya terang yang mereka lihat. yang membuat kota kecil mempunyai wisata budaya dan sejarah yang unik karena kejadian bersejarah tersebut menghasilkan festival Bakar Tongkang yang diadakan setiap tahunnya secara rutin dan juga festival ini sudah masuk dalam Top 10 Calender of Events pariwisata (CoE) wonderful Indonesia 2019 Fahmi Usman selaku Kepala Dinas Pariwisata Provinsi Riau.

*Korespondensi Penulis:

E-mail: rianto@stptrisakti.ac.id
Perayaan acara ini diadakan di kelenteng Ing Hok King yang merupakan kelenteng tertua di Bagansiapiapi selama 3 hari 2 malam. Dalam festival ini wisatawan dapat menyaksikan preosesi pembakaran replika Tongkang yang dibakar berlangsung dan juga ritual-ritual sembayang yang di lakukan masyarakat orang Tionghua disana yang meminta rejeki pada saat sembayang dan berjanji akan kembali jika permintaan terwujud dan juga di adakan konser yang mendatangkan artis-artis dari Taiwan, Malaysia, hingga artis local. Diramaikan Pak $\mathrm{Ka}$ jiong dari Taiwan langsung untuk merayakan festival Bakar Tongkang ini. Tidak hanya dari luar negeri saja tentunya di ramaikan juga oleh lokal seperti tahun ini 2019 Festival ini di buka secara resmi oleh Bupati Rokan Hilir Bapak Suyanto, yang mengadakan pemeran foto Bagansiapiapi tempo dulu, membangun tempat foto yang instagramable, fashion Karnava dan dimeriahkan Marching Band. Parade atau fashion karnaval ini menampilkan konsep yang merupakan paduan berbagai budaya yang ada di Bagansiapiapi yakni Budaya Tionghua, Budaya melayu hingga Budaya jawa. Dan Juga di pasangnya ratusan payung cantic bergantungan untuk memperindah mempercantik suasana kota dan instagramable. Yang bertujuan untuk menyukseskan acara dan mengundang pengunjungan wisatawan nusantara maupun mancanegara.

Nama Festival Bakar Tongkang ini sudah mendunia. Dibuktikan dengan tahun ini tercatat hampir 75.000 wisatawan datang menyaksikan festival Bakar Tongkang yang terus meningkat berdasarkan data yang 
tercatat. Berikut statistik kunjungan Turis Wonderful Event Bakar Tongkang.

\section{Tabel 1}

Jumlah Pengunjung Event Bakar Tongkang Bagansiapiapi

\begin{tabular}{cccc}
\hline No & Tahun & $\begin{array}{c}\text { Jumlah } \\
\text { Pengunjung }\end{array}$ & Persentase \\
\hline 1 & 2016 & 47.938 Jiwa & \\
\hline 2 & 2017 & 48.125 Jiwa & $0.39 \%$ \\
\hline 3 & 2018 & 71.000 Jiwa & $47,53 \%$ \\
\hline 4 & 2019 & 74.800 Jiwa & $5,35 \%$
\end{tabular}

Sumber: Dinas Pariwisata Provinsi Riau

Berdasarkan latar belakang dan data kepariwisataan Provinsi Riau wisatawan yang datang terus meningkat tiap tahunnya pada Festival Bakar Tongkang di Bagansiapiapi. Tujuan dari penulisan ini adalah untuk menganalisis potensi serta dampak yang terjadi karena perhelatan atraksi budaya Bakar Tongkang di kota Bagansiapiapi.

\section{METODE}

Dalam penelitian mengunakan penelitian kualitatif yang bertujuan untuk memahami dan meringkas sebuah fenomena dan realitas spsial yang terjadi di masyarakat pada Potensi Perhelatan Budaya Bakar Tongkang sebagai salah satu Atraksi Budaya di Riau dan dampak apa yang ditimbulkan dari perhelatan ini. Menurut (Sugiyono, 2017) penelitian kualitatif adalah metode penelitian yang berlandaskan pada filsafat postpositivisme, digunakan untuk meneliti pada kondisi objek yang alamiah, (sebagai lawannya adalah eskperimen) dimana peneliti adalah sebagai instrument kunci, teknik pengumpulan data dilakukan secara triangulasi (gabungan), analisis data bersifat induktif/kualitatif, dan hasil penelitian kualitatif lebih menekankan makna dari pada generalisasi.
Miles and Huberman (dalam Sugiyono, 2015: 337) mengemukakan bahwa aktivitas dalam analisis data kualitatif dilakukan secara interaktif dan berlangsung secara terus menerus sampai tuntas, sehingga datanya sudah jenuh. Teknik analisis menurut Miles and Huberman yaitu pengumpulan data (data collection), reduksi data (data reduction), penyajian data (data display), dan penarikan kesimpulan (conclusion drawing/ verification).

Menurut moleong dalam Setyowati (2011 : 70) Pemeriksaan terhadap keabsahan data pada dasarnya, selain digunakan untuk menyanggah balik yang dituduhkan kepada penelitian kualitatif yang mengatakan tidak ilmiah, juga merupakan sebagai unsur yang tidak terpisahkan dari tubuh pengetahuan penelitian kualitatif.

Tempat Pelaksanaan Penelitian ini adalah di Kota Bagansiapiapi .Dan lokasi ini merupakan satu-satunya tempat perhelatan budaya bakar tongkang yang ada di Indonesia dan perhelatan ini tetap eksis dan tetap dilestarikan di Bagansiapiapi.

\section{TEMUAN DAN PEMBAHASAN}

\section{A. Bagansiapiapi Heritage}

Destinasi wisata sejarah ini terdiri dari beberapa situs peninggalan masa pemerintah kolonial belanda dan situs kebudayaan masyarakat bagansiapiapi. Bagansiapiapi dikenal sebagai kota pusat pemerintahan yang sudah berusia ratusan tahun.

Tabel 2

Daftar Bagansiapiapi Heritage

\begin{tabular}{ll} 
No. & $\begin{array}{l}\text { Destinasi } \\
\text { Wisata }\end{array}$ \\
\hline
\end{tabular}




\begin{tabular}{ll}
\hline & Gedung \\
& Daerah Datuk \\
Batu Hampar
\end{tabular}

Rumah Kontrolir Belanda yang di bangun pada tahun 1903.

\begin{tabular}{|c|c|c|}
\hline \multirow{7}{*}{2} & & Pelabuhan \\
\hline & & Belanda \\
\hline & & dibangun \\
\hline & Kantor & tahun 1912 , yang \\
\hline & Cukai & saat \\
\hline & Bagansiapiapi & menyisakan Tiang \\
\hline & & $\begin{array}{l}\text { besi pelabuhan } \\
\text { dan gedung kantor }\end{array}$ \\
\hline
\end{tabular}

\begin{tabular}{|c|c|c|}
\hline 3 & $\begin{array}{l}\text { Tugu } \\
\text { Perjanjian }\end{array}$ & $\begin{array}{l}\text { Situs Warisan } \\
\text { yang } \\
\text { merefleksikan } \\
\text { kebudayaan } \\
\text { masyarakat } \\
\text { keturunan } \\
\text { Tionghua di } \\
\text { Bagansiapiapi } \\
\text { yang di bangun } \\
\text { pada tahun 1950- } \\
\text { an. }\end{array}$ \\
\hline 4 & $\begin{array}{l}\text { Klenteng ING } \\
\text { HOK KIM }\end{array}$ & $\begin{array}{l}\text { Berlokasi pada } \\
\text { pusat } \\
\text { Bagansiapiapi } \\
\text { yang didirikan } \\
\text { pada abad ke- } 19 .\end{array}$ \\
\hline 5 & $\begin{array}{l}\text { Rumah } \\
\text { Kapitan }\end{array}$ & $\begin{array}{l}\text { Situs rumah } \\
\text { kapitan } \\
\text { Bagansiapiapi } \\
\text { yang di bangun } \\
\text { pada abad ke-19. }\end{array}$ \\
\hline 6 & $\begin{array}{l}\text { Water } \\
\text { Leiding }\end{array}$ & $\begin{array}{l}\text { Dibangun pada } \\
\text { kurun 1920-1930 } \\
\text { yang didirikan } \\
\text { oleh pemerintah } \\
\text { bersama tokoh } \\
\text { warga } \\
\text { Bagansiapiapi. }\end{array}$ \\
\hline 7 & $\begin{array}{l}\text { RSUD RM } \\
\text { PRATOMO }\end{array}$ & 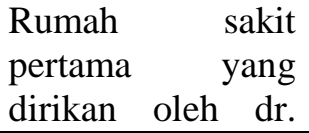 \\
\hline
\end{tabular}

\begin{tabular}{|c|c|c|}
\hline & & $\begin{array}{l}\text { RM PRATOMO } \\
\text { pada tahun } 1911 .\end{array}$ \\
\hline 8 & Gedung BRI & $\begin{array}{l}\text { Didirikan pada } \\
\text { tahun } 1918 \text { oleh } \\
\text { sebuah yayasan } \\
\text { yang dibentuk } \\
\text { oleh pemerintah } \\
\text { hindia } \\
\text { VEREENIGING) } \\
\text { bersama-sama } \\
\text { dengan tokoh } \\
\text { warga } \\
\text { Bagansiapiapi. }\end{array}$ \\
\hline 9 & Asrama Polisi & $\begin{array}{l}\text { Awalnya adalah } \\
\text { ZiekenHuis Atau } \\
\text { rumah sakit yang } \\
\text { didirikan kurun } \\
\text { periode 1938-1940 } \\
\text { oleh Missionaris. }\end{array}$ \\
\hline 10 & $\begin{array}{l}\text { Tangsi Polisi } \\
\text { Polsek } \\
\text { BAngko }\end{array}$ & $\begin{array}{l}\text { Tangsi Polisi } \\
\text { Hindia Belanda Di } \\
\text { Bagansiapiapi } \\
\text { Yang didirikan } \\
\text { menjelang perang } \\
\text { dunia II }\end{array}$ \\
\hline 11 & $\begin{array}{l}\text { Pertokoan } \\
\text { Jalan } \\
\text { Peniagaan }\end{array}$ & $\begin{array}{l}\text { kawasan } \\
\text { pertokoan yang } \\
\text { dibangun pada } \\
\text { tahun 1920-an di } \\
\text { Bagansiapiapi. }\end{array}$ \\
\hline
\end{tabular}

Diadakannya

Festival Bagansiapiapi Heritage biasanya dilaksanakan menjelang Pelaksanaan Bakar Tongkang yang sudah dijalankan selama 2 kali yaitu 2018 dan 2019. Dengan tujuan untuk mengenal destinasi pada khalayak wisatawan dan media yang biasanya ramai berdatangan pada ritual tahunan.

\section{B. Bakar Tongkang}

Bakar Tongkang merupakan tradisi yang sudah dilaksanakan secara turun temurun untuk menghormati dan melestarikan warisan nenek moyang oleh para etnis 
tionghoa di Provinsi Riau. Bakar Tongkang atau Bahasa Hokkien disebut Go Gek Cap Lak atau penanggalan imlek bulan ke-5 (lima) tanggal 16 (enam belas) yang sudah menjadi ritual tahunan masyarakat bagansiapiapi, seperti namanya ini adalah prosesi membakar replika kapal yang disebut tongkang.

\section{Gambar 1}

\section{Foto kondisi Bakar Tongkang zaman dulu}

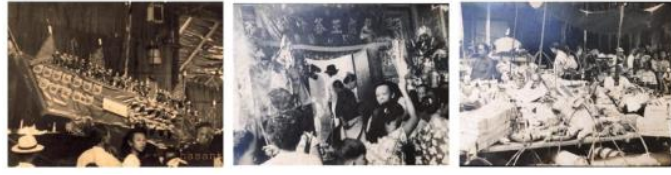

Sumber: Hasanyo Yang

Perhelatan Bakar Tongkang dilaksanakan sangat meriah dan diikuti oleh masyarakat lokal maupun wisatawan yang berkunjung. Perhelatan ini mempunyai Rundown atau Jadwal Event yang di dapatkan langsung dari Dinas Pariwisata.

Dalam prosesi perhelatan Bakar Tongkang dilaksanakan selama 3 hari 2 malam yang terdapat acara membakar replika tongkang yang di angkat oleh etnis tionghoa dari klenteng Ing Hok King Menuju sebuah lapangan untuk disembahkan, atraksi tang ki (tatung), serta para masyarakat bagansiapiapi mengikuti acara dengan membawa Hio (Dupa) untuk meminta rejeki pada sembayang dan berjanji akan kembali jika permintaan terwujud.

\section{Gambar 2}

\section{Poster konser Bakar Tongkang dan Pak ka ciong}

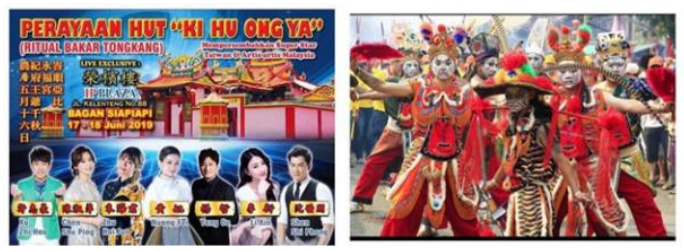

Sumber: Panitia pelaksana \& Dokumentasi @ebbie.vebriadrian

\section{Prosesi perhelatan bakar tongkang}

Hari Pertama Dalam Jadwal Event Wisata Nasinal Festival Bakar Tongkang yang diselenggarakan oleh pemerintah yakni Bakar Tongkang Fashion Carnaval dibuka secara resmi oleh Bupati Rokan Hilir (Rohil) Suyatno pada tanggal (17/6/2019) peserta dengan kostum menarik dengan berbagai unsur dengan tema keberagaman dari pesona Rokan Hilir dan di adakannya pentas negri seribu.

Hari kedua diadakan Bagansiapiapi Haritage Walk untuk mengeksplor situs sejarah yang ada di Bagansiapiapi yang sebelumnya di buka dan diresmikan oleh Bupati Rokan Hilir.

Hari ketiga yang merupakan hari puncak Acara Bakar Tongkang dimulai dari persiapan mulai dari sembayang oleh panitia Bakar Tongkang di Klenteng Ing Hok King.

Ritual Bakar Tongkang digelar secara meriah dan totalitas tiap tahunnya. Dengan ukuran replika tongkang yang berukuran hingga 8.5 meter, lebar 1.7 meter, berat mencapai $400 \mathrm{~kg}$ dan dengan biaya pembuatan replika tongkang sekitar 20 jutaan. Replika tongkang akan disimpan satu malam di klenteng Ing Hok King, disembayang dan kemudian di bawa menuju tempat pembakaran replika Tongkang.

Peserta atau masyarakat yang mengikuti akan berkumpul di klenteng Ing Hok King yang menjadi titik kumpul. Ritual Bakar Tongkang ini diikuti 100 kelenteng yang ada di Bagansiapiapi dan kelompok yang meneteng Dian yang sudah berisi dewa untuk meramaikan acara Bakar Tongkang. (sumber: detik.com)

Tongkang akan di pinggul oleh sekelompok pria. Dimulai dari kelenteng dengan waktu jalan sesuai dengan arahan dewa melalui Tangki (tatung) menuju tempat pembakaran Tongkang. Ritual ini dikuti oleh berbagai tingkat usia. Berbaris berkumpul di depan kelenteng dengan membawa hio yang telah di bakar ujungnya 
dan berjalan mengikuti tongkang. Para peserta harus menahan sesak dan debu hio sepanjang jalan menuju kelokasi pembakaran Tongkang yang memakan waktu hampir 1 jam atau $2 \mathrm{~km}$. Tetapi peserta tetap hikmat mengikuti prosesi Bakar Tongkang. Biasanya peserta kebanyakan bertujuan untuk meminta rejeki maupun kesehatan dan berjanji untuk kembali jika permintaan terwujud.

\section{Gambar 3}

\section{Peta Jalur Perhelatan Bakar Tongkang}

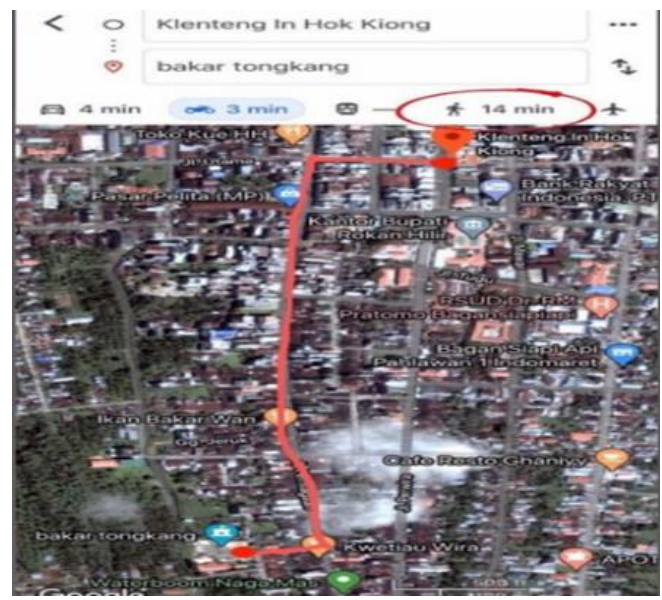

Sumber: Peneliti

Di Lokasi pembakaran, tongkang tidak serta merta dibakar, melainkan menunggu petunjuk dari tangki (tatung). proses ini, mulai dari prosesi pelepasan arakarakan tongkang hingga acara puncak pembakaran, memakan waktu 3 hingga 4 jam. diperlukan kesiapan fisik dan kebugaran tubuh jika ingin mengikuti dan menikmati secara langsung tradisi budaya bakar tongkang. (sumber: Buku Dinas Pariwisata Pemuda dan Olahraga Kabupaten Rokan Hilir)

Prosesi yang ditunggu-tunggu bagi turis ritual bakar tongkang adalah saat jatuhnya tiang tongkang yang di bakar, apakah jatuhnya menghadap kearah laut atau ke darat; bermakna hoki yang diharapkan untuk tahun itu mengacu pada arah jatuhnya tiang tongkang: rezeki dari arah laut atau arah darat menurut kepercayaan warga setempat.

\section{Gambar 4}

Kondisi Ritual Perhelatan Bakar Tongkang

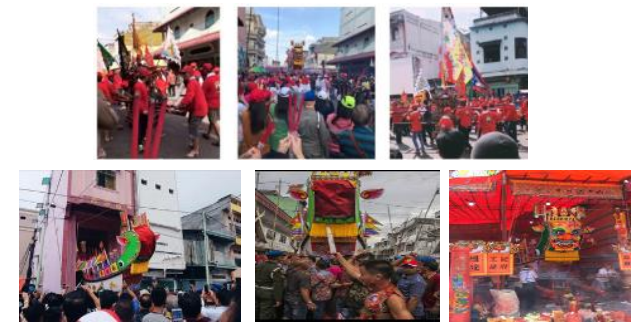

Sumber: Peneliti

\section{A. Dampak Perhelatan Budaya Bakar Tongkang terhadap Kota Bagansiapiapi}

Dampak dari Perhelatan Budaya Bakar Tongkang tentunya ada yang positif dan negatif. Positif apabila masyarakat dan pemerintah setempat merasakan manfaatnya seperti kondisi perekonomian daerah yang meningkat dikarenakan Perhelatan budaya ini. Negatif apabila masyarakat merasa terganggu dan merugikan.

Dampak yang paling besar bisa dilihat dari hasil observasi peneliti adalah peningkatan ekonomi kota Bagansiapiapi. Terbukti dari peningkatan pendapatan usaha pariwisata seperti Akomondasi (penginapan), rumah makan, Retail store, rental mobil, dan pedagang kaki lima. Dari semua yang peneliti wawancarai mengalami peningkatan pendapatan pada usaha mereka. Dan secara langsung dan tidak langsung juga memberi dampak positif bagi masyarakat lokal seperti penjualan jajanan, minuman, oleh-oleh hingga lapangan kerja dan juga dampak baik terhadap pemerintah khususnya di Kota Bagansiapiapi yakni pertumbuhan ekomoni daerah dan Pendapatan Asli Daerah (PAD) dalam sektor pariwisata.

Tabel 3

\section{Jumlah Pengunjung Event Bakar Tongkang Bagansiapiapi}




\begin{tabular}{llll}
\hline No & Tahun & $\begin{array}{l}\text { Jumlah } \\
\text { Pengunjung }\end{array}$ & $\begin{array}{l}\text { Persentase } \\
\%\end{array}$ \\
1 & 2016 & 47.938 Jiwa & \\
2 & 2017 & 48.125 Jiwa & $0,39 \%$ \\
3 & 2018 & 71.000 Jiwa & $47,53 \%$ \\
4 & 2019 & 74.800 Jiwa & $5,35 \%$ \\
\hline \multicolumn{5}{l}{ Sumber: Dinas Pariwisata Provinsi Riau }
\end{tabular}

\section{SIMPULAN}

Berdasarkan hasil penelitian tentang dampak yang ditimbulkan dari perhelatan Budaya Bakar Tongkang di Bagansiapiapi. dampak yang paling di rasakan adalah dampak positif terutama pemutaran ekonomi daerah t dan Pendapatan Asli Daerah (PAD), dapat dilihat dari hasil observasi peneliti sejumlah Usaha pariwisata seperti akomondasi penginapan (Hotel), Restoran (Rumah Makan), Rental Mobil, Retail store dan pedagang kaki lima.

Dampak juga dirasakan oleh Masyarakat lokal seperti adanya lowongan kerja yang ditimbulkan dari Perhelatan budaya ini dalam memenuhi kegiatan pariwisata seperti menjual jajanan, menjadi supir, menjadi resepsionis dan sebagainya.

\section{DAFTAR PUSTAKA}

Aryanto, R. (2018). Jurnal Ilmu Sosial, Analisis dampak ekonomi dari kebudayaan bakar tongkang di Bagansiapiapi Kecamatan Bangko Kabupaten Rokan Hilir.

HEri, M. d. (2019). Jurnal Pendidikan, Implementasi pendidikan karakter melalui budaya sekolah di SD dan Kotagede Yogyakarta.
Lunchman, K. W. (2017). Jurnal

Administrasi bisnis, $\begin{aligned} & \text { Strategi } \\ & \text { pengembangan destinasi } \\ & \text { budaya. }\end{aligned}$

Rivaldi, A. (2019, 08 06). Jadwal dan

JADWAL DAN HARGA FERRY

BATAM JET SEMUA RUTE.

Diambil kembali dari

RIVALDI.NET:

https://rivald.net/jadwal-dan-harga-

tiket-kapal-ferry-batam-jet/

Rodzi, F. (2019, JUNI 20). FOTO-FOTO

KEMERIAHAN RITUAL BAKAR

TONGKANG DI BAGANSIAPIAPI.

Diambil kembali dari RIAUONLINE:

https://www.riauonline.co.id/wisata/r

ead/2019/06/20/foto-foto-

kemeriahan-ritual-bakar-tongkang-

di-bagansiapiapi.

Siti, Y. d. (2017). Pengaruh jumlah

wisatawan terhadap pedapatan asli daerah di Kabupaten Pandeglang Tahun 2005 - 2015.

Situmorang, D. (2019). Tinjauan hukum terhadap perlindungan hukum hak wisatawan daerah wisata Baktiraja Kabupaten Humbang Hasundutan.

\section{WEBSITE}

Syahrifah, F. (2019, JUNI 19). MENYINGKAP KEBESARAN SEJARAH KOTA BAGANSIAPIAPI. Diambil kembali dari LIPUTAN 6: https://m.liputan6.com/lifestyle/rea d/3993048/menyingkap-kebesaransejarah-kota-bagansiapiapi-lewatheritage 
Versi Online:

https://journal.ubm.ac.id/index,php/hospitality-pariwisata

Doi: http://dx.doi.org/10.30813/jhp.v7i2.3023

Hasil Penelitian
Jurnal Hospitality dan Pariwisata Vol.7 (No.2): 120 - 126. Th. 2021 p-ISSN: 2442-5222 e-ISSN: 2655-8165

Tanjung, C. A. (2019, 06 19). TRADISI

BAKAR TONGKANG DI RIAU

MENGHABISKAN DANA RP 600

JUTA. Diambil kembali dari

DETIKTRAVEL:

https://m.detik.com/travel/travelnews/d-4592284/tradisi-bakar-

tongkang-di-riau-habiskan-dana-rp600-juta. 